\title{
Observed Mean Residence Time Infinity
}

National Cancer Institute

\section{Source}

National Cancer Institute. Observed Mean Residence Time Infinity. NCI Thesaurus. Code C85769.

The observed mean residence time (MRT) extrapolated to infinity. 